\title{
Serum Magnesium Level in Hospitalized Nephrotic Syndrome Patients and Its Relation to Cholesterol
}

\author{
Chaudhury GN ${ }^{\mathrm{a}}$, Hanif $\mathrm{M}^{\mathrm{b}}$
}

\begin{abstract}
Background: Nephrotic syndrome (NS) is a common childhood renal disease all over the world. This study was designed to evaluate the magnesium level in patients with nephrotic syndrome and its relation to cholesterol.

Methods: An observational cross sectional study was conducted in the Department of Pediatrics, Dhaka Shishu Hospital, Dhaka from January 2015 to June 2015. Fifty four diagnosed cases of nephrotic syndrome admitted during the study period in this hospital were included in this study and patients of NS with associated illnesses such as diarrhoea, severe vomiting and already have metabolic disturbances and seizure were excluded in this study. Serum magnesium and cholesterol levels were assessed in every enrolled patients.

Results: The mean level of serum magnesium during initial attack was 2.28 \pm 0.36 , and it was $2.04 \pm 0.29$ during first relapse, $2.06 \pm 0.29$ during infrequent relapse and $1.76 \pm 0.32$ during frequent relapse. The difference found among the mean level of serum magnesium level in different pattern of nephrotic syndrome by ANOVA test (one way) was statistically significant $(P<0.01)$. All the patients had severely high cholesterol level and about $22 \%$ of them had $\mathrm{mg}$ level at $<1.8 \mathrm{mg} / \mathrm{dl}, 52 \%$ of them had $\mathrm{mg}$ level at $1.8-2.4 \mathrm{mg} / \mathrm{dl}$ and $26 \%$ of them had $\mathrm{mg}$ level $>2.4 \mathrm{mg} / \mathrm{dl}$. The p value is 0.1 which signifies statistically insignificant correlation between the mg level and cholesterol level. Inverse correlation with serum magnesium with serum cholesterol in children with nephrotic syndrome and that was statistically not significant $(r=-0.179, p=0.1)$.

Conclusion: Serum magnesium level is low in most(64.3\%) cases of frequent relapse nephrotic syndrome. Inverse correlation with serum magnesium with serum cholesterol in children with nephrotic syndrome and that was statistically not significant.
\end{abstract}

Key words: Nephrotic syndrome, magnesium, cholesterol.

(BIRDEM Med J 2017; 7(1): 12-16)

\section{Introduction}

The mineral magnesium is required by virtually every process in the body and deficiencies are fairly common. Magnesium helps regulate blood sugar levels, promotes normal blood pressure, and is known to be involved in energy metabolism and protein synthesis. There is an

\section{Author Informations}

a. Dr. Gulshan Nigar Chaudhury, FCPS (Pediatrics) Resident Medical Officer, Department of Rheumatology, Dhaka Shishu (Children) Hospital.

b. Dr. Mohammad Hanif, FCPS (Pediatrics) FRCP Professor and Head of the Department of Nephrology, Dhaka Shishu (Children) Hospital.

Address of Correspondence: Dr. Gulshan Nigar Chaudhury, Resident Medical Officer, Department of Rheumatology, Dhaka Shishu (Children) Hospital, Email: gulshan.chy@gmail.com

Received: June 25, 2016

Accepted: November 30, 2016 increased interest in the role of magnesium in preventing and managing disorders such as hypertension, cardiovascular disease, and diabetes. ${ }^{1}$

Nephrotic Syndrome (NS) is a clinical entity characterized by massive loss of urinary protein leading to hypoproteinemia resulting in edema. Hyperlipidemia is usually associated with Nephrotic Syndrome. ${ }^{2}$ Although pathophysiological aspects of hyperlipidemia have not been completely identified, hypoalbuminemia, increased lipoprotein synthesis and decreased lipoprotein lipase activity are described by various workers. ${ }^{3-6}$

The persistence and severity of lipid changes in serum correlates well with the duration and frequency of the relapses, even during remission which leads to increased risk of atherosclerosis in later life and the development of progressive renal injury. The intensity of 
hyperlipidemia is usually related to the severity of proteinuria ${ }^{7,8} . \mathrm{Mg}$ can act like a natural statin drug and lower bad cholesterol (LDL) reduce triglycerides and increase good cholesterol (HDL). To make cholesterol, it requires a specific enzymes called HMG-CoA reductase. $\mathrm{Mg}$ regulates this enzyme so as to maintain only a proper amount of cholesterol. The HMGCoA reductase enzyme is the exact same enzyme that is targeted and inhibited by statin drugs. The inhibiting process is similar to Mg's function except that $\mathrm{Mg}$ is the natural way. ${ }^{9,10,11}$

Biochemcal ration is a common phenomenon in all kidney diseases including nephrotic syndrome and as most intracellular magnesium is bound to proteins, membrane leakiness in nephrotic syndrome causes hypoalbuminemia as well as hypomagnesemia. Mg deficiency causes hypertrophy of jumtraglomerular apparatus located in the kidney. This releases renin which ultimately increases aldosteron, lowering serum $\mathrm{Mg}$ and $\mathrm{K} .{ }^{12,13}$ So Magnesium level should be checked as a part of evaluation of the severity of the kidney problems. And as serum magnesium level is related to cholesterol level and albumin, so proper supplementation of magnesium can properly manage the disease as they are altered in nephrotic syndrome.

A particular long list of prescription medications have been shown to reduce the body's supply of magnesium. Several types of diuretics, loop diuretics like frusemide and antibiotics have been shown to compromise magnesium status. Other medications that reduce the body's supply of magnesium include corticosteroids and immuno-suppressant drug cyclosporin ${ }^{1415}$. For these reasons the serum magnesium level in patients with idiopathic nephrotic syndrome is an important issue.

\section{Methods}

An observational cross sectional study was conducted in the Department of Pediatrics, Dhaka Shishu Hospital, Dhaka with 54sample cases from January 2015 to June 2015, . The Nephrotic cases were selected according to the criteria proposed by International study of kidney diseases in children (ISKDC), that is children with oedema, proteinuria (more than $3 \mathrm{gm}$ in $24 \mathrm{hrs} / 1.73 \mathrm{~m} 2$ ), hypoproteinemia (serum albumin less than $2.5 \mathrm{gm} / \mathrm{dl}$ ), hyperlipidemia ${ }^{13}$ (M.Phadke, Oct 1990). Exclusion Criteria: Children with liver disorders, oedema due to Kwashiorkor, oedema due to CCF and Children suffering from kidney diseases other than nephrotic syndrome. The samples were analysed for Protein profile (Serum Total protein, serum albumin, serum globulin, A:G ratio, urinary proteins, Blood urea \& serum creatinine), Total cholesterol was measured Nephrotic syndrome with initial levels measured within 24 hours of admission to the hospital. Data were collected by interview of the patients, clinical examination and laboratory investigations using the research instrument.

\section{Magnesium measurement}

The MG method was used on the Dimension(R) clinical chemistry system. It is an in vitro diagnostic test intended for the quantitative determination of magnesium in human serum, plasma and urine.

The magnesium method is a modification of the methylthymolblue(MTB) complexometric procedure described by Connerty, Lau and Briggs. The barium salt of ethylenebis (oxyethylenenitrilo) teraacetic acid (BaEGTA) is used to reduce interference due to calcium which also reacts with MTB.

\section{Cholesterol measurement}

Intended use: The CHOL method used on the Dimension $\AA$ clinical chemistry system is an in vitro diagnostic test intended for the quantitative determination of cholesterol in human serum and plasma.

Data were processed and analysed using software SPSS (Statistical Package for Social Sciences) version 22.The test statistics used to analyzed the data were descriptive statistics and correlation coefficient and student t test. Level of significance was set at 0.05 and $p<0.05$ was considered significant.

\section{Results}

In the present study mean age was $5.51( \pm 2.56)$ years, minimum age was 1 year and maximum age was 10 years, maximum age group was $>5$ years of old which was $53.7 \%$. majority of them were male baby $39(72.2 \%)$. Male female ratio 2:1. (Table $-\mathrm{I}$ ) 
Table I. Demographic characteristics of the study population

\begin{tabular}{lcc} 
& Number & Percentage \\
\hline Age in years & & \\
- $\quad 1 \mathrm{yr}$ & 02 & 3.7 \\
- $\quad 2-5 \mathrm{yrs}$ & 23 & 42.6 \\
- $\quad>5 \mathrm{yrs}$ & 29 & 53.7 \\
Mean SD & $5.51( \pm 2.56)$ & Range $1-10$ years \\
Sex & & \\
- Male & 39 & 72.2 \\
- Female & 15 & 27.8 \\
\hline Total & 54 & 100.0 \\
\hline
\end{tabular}

Presenting complaints show that majority of the patients had swelling of face (86.67\%), swelling of leg (75\%), swelling of abdomen (76.67\%) and cough $(65 \%)$. Swelling of genitalia, fever, abdominal pain, vomiting, respiratory distress, burning sensation during micturation were found in $28.33 \%, 43.33 \%, 36.67 \%$, $31.67 \%, 20 \%$ and $16.67 \%$ of cases respectively. (Table -II).

Table II. Distribution of patients by presenting complaints $(n=54)$

\begin{tabular}{lcc} 
& Number & Percentage \\
\hline Swelling of face & 52 & 86.67 \\
Swelling of leg & 45 & 75.00 \\
Swelling of abdomen & 46 & 76.67 \\
Swelling of genitalia & 17 & 28.33 \\
Fever & 26 & 43.33 \\
Pain abdomen & 22 & 36.67 \\
Vomiting & 19 & 31.67 \\
Cough & 39 & 65.00 \\
Respiratory distress & 12 & 20.00 \\
Burning sensation during & 10 & 16.67 \\
micturation & & \\
\hline
\end{tabular}

Among nephrotic syndrome cases $17(28.33 \%)$ patients were in first attack, $14(23.33 \%)$ were in $1^{\text {st }}$ relapse, $16(26.67 \%)$ were in infrequent relapse and $13(21.67 \%)$ were in frequent relapse nephrotic syndrome. (Table-III).

Table III. Distribution of patients by type of attack

\begin{tabular}{lcc} 
Type of attack & Number & Percentage \\
\hline First Attack & 15 & 27.8 \\
First Relapse & 12 & 22.2 \\
Infrequent Relapse & 13 & 24.1 \\
Frequent Relapse & 14 & 25.9 \\
\hline Total & 54 & 100.0 \\
\hline
\end{tabular}

The mean level of serum magnesium during initial attack was $2.28 \pm 0.36$, and it was $2.04 \pm 0.29$ during first relapse, $2.06 \pm 0.29$ during infrequent relapse and $1.76 \pm 0.32$ during frequent relapse. The difference found among the mean level of serum magnesium level in different pattern of nephrotic syndrome by ANOVA test (one way) is statistically significant $(\mathrm{P}<0.01)$. (Table IV)

Table IV. Magnesium status in different states of nephrotic syndrome $(\mathrm{n}=54)$

\begin{tabular}{lcc} 
Type of Attack & $\mathrm{N}$ & $\begin{array}{c}\text { Magnesium } \\
\text { Level }(\mathrm{mg} / \mathrm{dl}) \\
{[\mathrm{Mean} \pm \mathrm{SD}]}\end{array}$ \\
\hline Initial attack & 15 & $2.28 \pm 0.36$ \\
1st relapse & 12 & $2.04 \pm 0.29$ \\
Infrequent relapse & 13 & $2.06 \pm 0.29$ \\
Frequent relapse & 14 & $1.76 \pm 0.32$ \\
*P Value & & $<0.01$ \\
\hline
\end{tabular}

*Anova Test

All the patients had severely high cholesterol level and about $22 \%$ of them had $\mathrm{mg}$ level at $<1.8 \mathrm{mg} / \mathrm{dl}, 52 \%$ of them had $\mathrm{mg}$ level at $1.8-2.4 \mathrm{mg} / \mathrm{dl}$ and $26 \%$ of them had $\mathrm{mg}$ level $>2.4 \mathrm{mg} / \mathrm{dl}$. The $\mathrm{p}$ value is 0.1 which signifies statistically insignificant correlation between the mg level and cholesterol level. (Table V). 
Table V. Association between magnesium level with cholesterol level

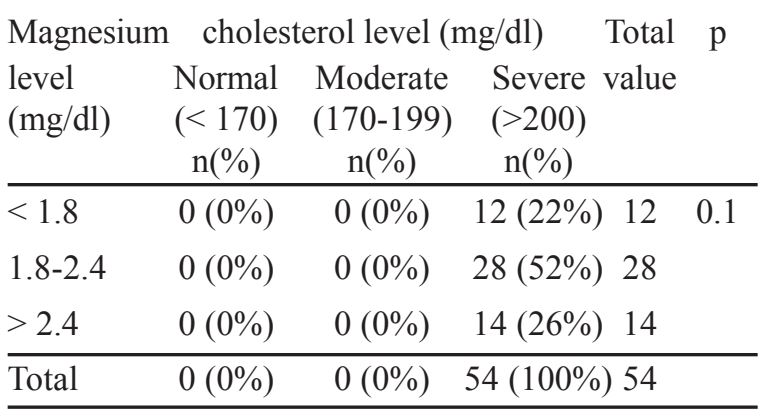

Serum magnesium level is low in most cases of frequent relapse nephrotic syndrome.

The present study also reveals there is inverse correlation between serum magnesium level with serum cholesterol, the correlations were statistically not significant $(\mathrm{r}=$ $0.179, \mathrm{p}=0.1)$.(Fig.-1)

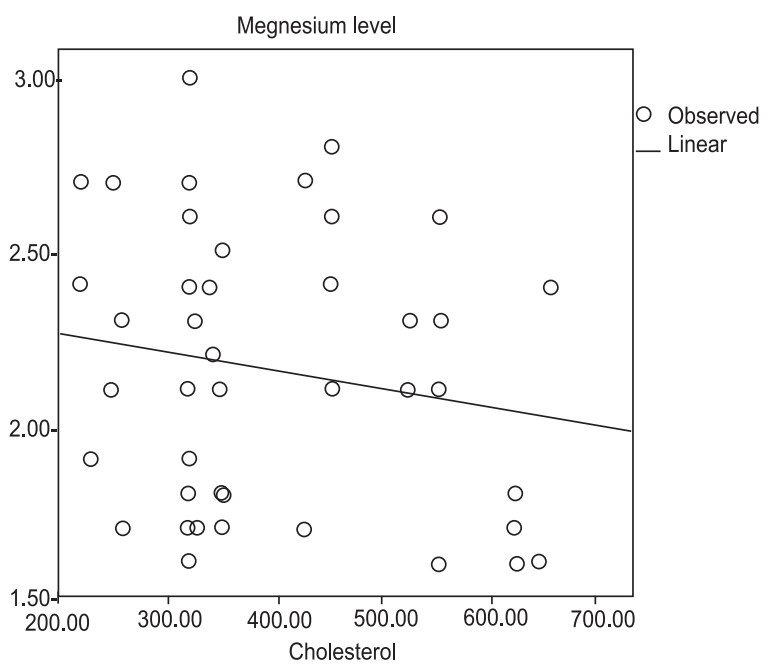

Figure 1: Correlations between serum magnesium with serum cholesterol in children with nephrotic syndrome.

\section{Discussion}

The observational cross sectional study was carried out in department of Nephrology Dhaka Shishu (Children) Hospital. There were total 54 children enrolled in the study out of these 39 males and 15 female children in the study group. In our study, we found the relation of serum magnesium with serum cholesterol. The mean age was $5.51( \pm 2.56)$ years, minimum age was 1 year and maximum age was 10 years, maximum age group was $>5$ years of old which was $53.7 \%$. majority of them were male baby $39(72.2 \%)$. male female ratio was $2.6: 1$.

Hypercholesterolemia is an important feature of nephrotic syndrome. Present study showed, raised level of total cholesterol in first attack,first relapse, infrequent relapse \& frequent relapse during active disease.Arije et $\mathrm{al}^{16}$ observed a significant fall from the high mean pretreatment level of total cholesterol and LDL cholesterol at 4,8,12 weeks of treatment while the fall in mean TG level only became significant at 8 weeks. The mean HDL cholesterol did not change significantly throughout the treatment. Whereas in cases of relapses, even at the end of steroid therapy there was no significant reduction in serum lipids and found to be persistently high. Merouaniet a ${ }^{17}$ observed hyperlipidemia during the active phase of the disease and disappeared with resolution of proteinuria and was persistently abnormal in frequency. Tsukaharaet $\mathrm{al}^{18}$ observed that children with frequently relapsing nephrotic syndrome have prolonged periods of hypercholestrelemia, even during clinical remission. We noticed that the degree of lipid increase was not that high as reported by Western workers. Milne reported that the total cholesterol in nephrotic syndrome may be higher than $1000 \mathrm{mg} \%{ }^{19}$ In Dyaneshet $\mathrm{al}^{\mathbf{2 0}}$ study the mean total cholesterol was $422.61 \mathrm{mg} \%$ and highest value was $676 \mathrm{mg} \%$. Banerjee et al in his study observed that the mean total cholesterol was $341 \mathrm{mg} \%$ and the highest value was $641 \mathrm{mg} \%{ }^{21}$

Present study showed significant difference of serum magnesium level in frequent relapse but similar serum magnesium level were found in first attack, first relapse and infrequent relapse nephrotic syndrome. Present study also revealed there is inverse correlation between serum magnesium level with serum cholesterol, the correlations were statistically not significant $(\mathrm{r}=-0.179$, $\mathrm{p}=0.1)$. Kobayashi A study in Japan showed serum magnesium was inversely correlated with total cholesterol level. ${ }^{22}$ Kobayashi A study in Japan, serum magnesium level was significantly reduced in the untreated condition of disease. Serum magnesium level was gradually elevated to the normal range as the disease improved It is fairly well established that aldosterone plays an important part in the regulation of magnesium metabolism and incorrect renal excretion of this ion. ${ }^{23}$ 
There is however, meagre information available concerning magnesium metabolism in the nephroticsyndrome.Proshad, Flink and Mc-Collister described that in the nephrotic syndrome the total magnesium was some what lower than normal, probably because of hypoprotinaemia and that the percentage of ultrafiltrable magnesium was increased in some patients associated with hypoalbunaemia ${ }^{24}$.

From these data, hypomagnesaemia in the nephrotic syndrome may be partly due to secondary hyperaldosteronism which is thought to develop in nephrotics with generalized oedema and partly due to loss of protein.

\section{Conclusion}

Our study concludes that serum magnesium level is low in most cases of frequent relapse nephrotic syndrome. There is inverse correlation between serum magnesium levelwith serum cholesterol, but the correlation is statistically not significant.

\section{Limitation}

It was a hospital based study. Sample size of this study was not so large to give much strength of the study.

\section{Recommendation}

Furthur study should be done to look for any renal structural abnormality particularly tubular problem in those patients.Furthermulticentred study should also be under taken.

\section{Conflict of interest: None}

\section{References}

1. Gowenlock AH, McMurray JR, Mclauchlan DM. Varley's Practical Clinical Biochemistry, 5th Ed. Heinemann Medical: London, UK. 1988; 408-410

2. Adewoye HO, Fawibe JF. Serum Albumin Level in an Urban Nigerian Population.Br J Nutr 1978; 40: 439-42.

3. Craing GC, Willis NC, Hodson EM. Incidence of Nephrotic Syndrome in Children in Australia. Pediatr Nephrol. 2000; 11: 111-16.

4. Bhandari B, Mandowara SL. Lipoprotein profile in nephrotic syndrome, Indian pediatrics, 1980; 11: 416-19.
5. David CW. Bernard DB. Lipid abnormalities in the nephrotic syndrome, Am J Kidney Dis 1994; 23(3): 331-46.

6. Banerjee SK, Sarkar AK, Chugh KS, Bansal VK. ChhuttaniPN. Serum lipids in nephrotic syndrome, JAPI 1982; 71: 651-57.

7. Sah JP, Pandey R, Jaiswal S, Sharma B, Chaudhary SS. Correlation of Hypoproteinemia and Hypoalbuminemia with Hypercholesterolemia in the Children with Nephrotic Syndrome. RRJoHP 2013; 3(2): 1-11.

8. Thomas E.M., Rosenblum AH, Lander HB, Fisher R. Relationship between blood lipid and blood protein levels in nephrotic syndrome, Amer J Dis. Child, 1951; 81: 207.

9. Peters JP, Man EB. The inter relationship of Serum lipids in patients with diseases of kidneys, J Clin Invest, 1943; 22: 721.

10. Bagga, A, Mantan M. Nephrotic syndrome in children”. Indian Journal, Medical Research, 2003; 122( 6): 13-28

11. Phadke M, S. Bhave. Idiopathic Nephrotic Syndrome: The frequent relapse. Indian Paediatrics; 1990; 27: 1034-38.

12. Benakappa D.G, SubbaRao A, Sastry N.S.C. Low density lipoprotein levels in children with nephrotic syndrome, Indian pediatrics, 1976; 13(4): 1976, 287-89.

13. Arije A, Erasmus RT, Anjorin S.A, Plasma lipids and lipoproteins cholesterol distributions in nephrotic syndrome patients during short term steroid treatment. Cent Afr J Med, 1993; 39(10): 211-15.

14. David CW. Bernard DB. Lipid abnormalities in the nephrotic syndrome, Am J Kidney Dis 1994; 23(3): 331-46.

15. Dnyanesh DK, Dnyanesh S, Shenoy V. A Study of Serum Lipids in Nephrotic Syndrome in Children, Journal of Dental and Medical Sciences (IOSR-JDMS) 2014; 13(3): 01-06

16. Banerjee SK, Sarkar AK, Chugh KS, Bansal VK. ChhuttaniPN. Serum lipids in nephrotic syndrome JAPI. 1982; 71: 651-57.

17. Kobayashi A. Serum magnesium level in Idiopathic nephroticsyndrome. PaediatrUniv 1968;15:12-16.

18. Horton R, Biglieri EG. Effect of aldosterone on the metabolism of magnesium. JClin Endocrin 1962;22:118792.

19. Prasad, A. S., Flink, F. B. and McCollister, R.: Ultrafiltration studies on serum magnesium in normal and diseased states, J, Lab \& clin. Med., 1961; 58: 531. 